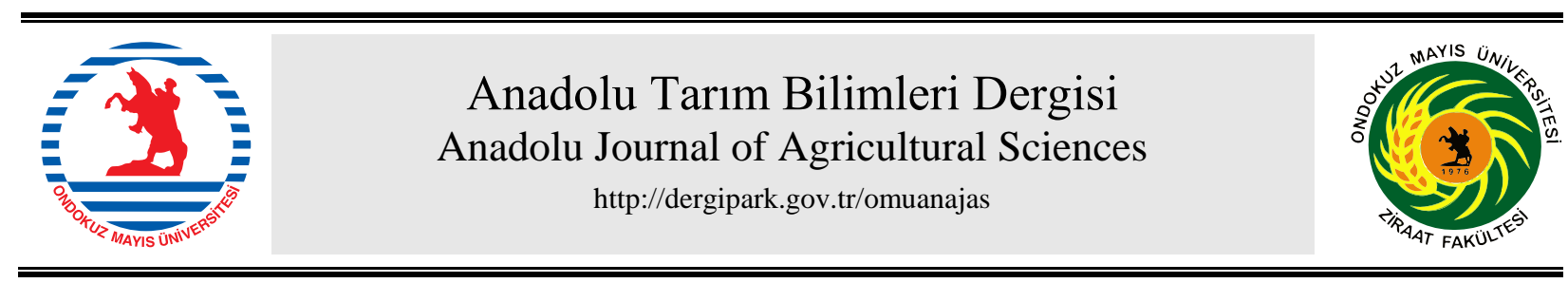

Araştırma/Research

Anadolu Tarım Bilim. Derg./Anadolu J Agr Sci, 35 (2020)

ISSN: 1308-8750 (Print) 1308-8769 (Online)

doi: $10.7161 /$ omuanajas.623265

\title{
Seçilmiş Üstün Oryantal Tütün Hatlarının Bazı Morfolojik ve Fenolojik Özelliklerinin Belirlenmesi
}

\author{
Dursun Kurt ${ }^{\mathrm{a}^{*}}$, Güngör Y1lmaz \\ ${ }^{a}$ Ondokuz Mayıs Üniversitesi, Bafra Meslek Yüksekokulu, Bitkisel ve Hayvansal Üretim Bölümü, Samsun, Türkiye \\ ${ }^{b}$ Tokat Gaziosmanpaşa Üniversitesi, Ziraat Fakültesi, Tarla Bitkileri Bölümü, Tokat, Türkiye
}

*Sorumlu yazar/corresponding author: dursun.kurt@ omu.edu.tr

Geliş/Received 22/09/2019 Kabul/Accepted 29/11/2019

\begin{abstract}
ÖZET
$\mathrm{Bu}$ çalışma ile Basma tipi tütün hatlarının fenolojik ve morfolojik olarak tanımlanması, tütün 1slahı konusunda yapılacak çalışmalara materyal hakkında bilgi verilmesi hedeflenmiştir. Tarla denemeleri Orta Karadeniz Bölgesi’nde tütün üretiminin en fazla olduğu Bafra, Erbaa ve Gümüşhacıköy'de 4 farklı arazide yürütülmüştür. Morfolojik bakımdan yaprak tipi, yaşmak eni, aya şekli, yaprak ucu şekli, aya kabarcıklığı, yaprakta ondülelik ile alt yüzey orta damar rengi ve fenolojik bakımdan çiçeklenme zamanı, taç yaprak rengi ile çiçek kümesi şekli parametreleri incelenmiştir. Elde edilen sonuçlara göre; yaprak tipi bakımından genotiplerin tamamı yaşmaklı, yaşmak eni bakımından \%84'ü orta-geniş yaşmak enine sahip, aya şekli bakımından \%92'si dar yada geniş eliptik, \%92'si orta sivri yada sivri yaprak ucuna sahiptir. Çiçeklenme zamanı bakımından genotiplerin \%32'si geçci karakterli, \%72'sinin taç yaprak rengi açık pembe ve tamamının çiçek kümesi şekli küreseldir.
\end{abstract}

Determination of Selected Superior Oriental Tobacco Lines with Some Morphological and Phenological Characteristics

\section{ABSTRACT}

In this study, it is aimed to define the Basma type tobacco lines as phenological and morphological. In addition, it is aimed to give information about the materials to be used in the studies on tobacco breeding. Field trials were conducted in 4 different locations in Bafra, Erbaa and Gümüşhaciköy districts where tobacco production was highest in the Central Black Sea Region. As morphological parameters, leaf type, width at blade, shape of blade, leaf tip shape, blistering of blade, undulations of margin and color of midrib on lower side and as phenological parameters, time of flowering, color of corolla and shape of inflorescence have been investigated. According to the results, all genotypes in terms of leaf type are sessile. $84 \%$ of the width at blade basis has medium or broad sessile width. $92 \%$ of the shape of blade is narrow elliptic or broad elliptic. $92 \%$ of the leaf tip shape is medium pointed or strongly pointed. According to time of flowering, 32\% of the genotypes have late characteristics. $\% 72$ of color of corolla are light pink color and the shape of inflorescence of all genotypes is spherical.

Anahtar Sözcükler:

Basma tipi

Karakterizasyon

Nicotiana tabacum L.

\section{Giriş}

Türkiye, yüksek kaliteli aromatik oryantal tütünlerin bilinen en büyük üreticisidir. Üretim, kaliteli sigara harmanlarında kullanılmak amacıyla çoğunlukla ihracata yönelik yapılmaktadır. Sigaralık tütünlerin istenen içim özelliklerini tek başına sağlayamaması harman yapma ihtiyacını doğurmaktadır.
Dünyada kullanılan en yaygın sigara harmanları virginia, burley ve oryantal tip tütünlerden oluşmaktadır. Oryantal tütünler, içerdikleri yüksek aroma özellikleri ile sigara harmanlarının içim özelliklerini düzenlemektedir. Tütün üretimimizin ve ihracatımızın yüksek olması tütünlerimizin, sigara harmanlarına sağladığı sslah edici kalitesinden kaynaklanmaktadır. 
Basma tipi tütünler küçük kısmen orta kıtalı olup, renkleri açık kırmızı ve koyu sarı tonları taşımaktadır. Kokulu olmaları en önemli özellikleridir. Dokusu ince, kalınca ve kadifemsi yapıya sahiptir. Bu özelliklerinden dolayı bazı özel sigara harmanları için sigara sanayinin önemli ve vazgeçilmez harman hatlarından birisidir (Çamaş ve ark., 2009a).

Basma tütün çeşitleri genel olarak, tarımsal özellikler yönünden incelendiğinde orta erkenci $(70$ gün), bitki boyu açısından orta boylu $(100 \mathrm{~cm})$ ve ortalama 30 adet ticari değeri olan yaprağa sahiptir. Bitkinin yapraklarını temsil eden 2. ellerde, yaprak ucunun hafif sivri, ortalama yaprak boyunun $20 \mathrm{~cm}$, yaprak eninin $10 \mathrm{~cm}$, ovalite katsayısının ve çaplar oranının iki olduğu bilinmektedir. Yaprak yüzeyi orta kabarcıklı olup, yaprak ayası aşağı sarkmalar şeklinde gövdeye sarılma özelliği göstermektedir. Yaprakların gövde üzerinde sarmal olarak dizildiği, divergens (phyllotaxy)'in $3 / 8$ ve çiçek renginin pembe olduğu da bir başka özelliğidir (Peksüslü, 1998; Çamaş ve ark., 2011). Erbaa'da yaptıkları çalışmalarda Çamaş ve ark. (2009b) ile Yılmaz ve Kınay (2011), Basma tütün tiplerinin yaprak biçimini eliptik, küçük-orta boyutlu, yaşmaklı, uç açısı sivri-az sivri, kalınca, ince damarlı, elastik, kokulu ve parlak-turuncu-açık kırmızı-kırmızı pişkin renk tonlarına sahip olduğunu bildirmişlerdir. Ege Tütün İhracatçıları Birliği Basma üreticilerine hazırladığı rehber kitabında, kaliteli ve yüksek verimli üretim için sertifikalı tohum kullanımının öneminden bahsetmiş ve Basma üretim alanlarına iki sertifikalı çeşit üretimini tavsiye etmiştir. Bunlar Xanthi $2 \mathrm{~A}$ ve Xanthi 81 'dir. Bu çeşitlerin 1lıman ve sıcak iklime sahip bölgelerde; düz, hafif veya çok eğimli, derin ve yüzeysel profilli, azotça orta ve potasyumca zengin süzek topraklarda iyi yetiştiği ifade edilmiştir. Yetiştiği bölgelerin ise; Erbaa, Taşova, Tokat, Niksar, Gümüşhacıköy, Vezirköprü, Havza, İnegöl, Orhaneli, Yenice ve Hamdibey olduğu aktarılmıştır (Anonim, 2012). Çeşit tanıtımlarının yapıldığ 1 kitapta Xanthi $2 \mathrm{~A}$; orta boylu, 28-30 yaprakl1, yaprakları kabarcıkl1, eliptik, küçük boyutlu, sivri uç açılı, yaşmaklı ve ince dokuludur. Dekara verimi $100 \mathrm{~kg}$, orta erkenci ve kuraklığa dayanıklıdır. Kurutulmuş yaprakları ince dokulu, altın sarıs1 ile turuncu aras1 renklere, \%1.6 nikotin ve $\% 15$ şeker içeriğine sahiptir. Xanthi 81 çeşidi ise uzun boylu, 30-32 yaprakl, yaprakları kabarcıkl, eliptik, orta-kısmen küçük boyutlu, yaprak ucu az sivri, yaşmaklı ve kalınca dokuludur. Dekara verimi 125-150 $\mathrm{kg}$, orta erkenci ve kuraklığa dayanıklıdır. Kurutulmuş yaprakları ince dokulu, altın sarısı ile turuncu arası renklere, $\% 1.7$ nikotin ve $\% 13$ şeker içeriğine sahiptir (Anonim, 2012). UPOV tarafindan bütün Nicotiana tabacum L. varyetelerinde kullanıma sunulan test rehberinde Xanthi 2A-81-101 çeşitlerine ait bazı özellikler paylaşılmıştır. Rehbere göre bu çeşitler kısaorta boylu, koltuk sürgünü olmayan, yaprakları bitkiye yapışık ve küçük boyutlu, orta yaşmaklı, geniş eliptik, orta-sivri uç açılı, orta kabarcıklı, ondüleliği orta, beyazımsı yeşil damarlı, orta-erkenci, küresel çiçekli ve çiçek rengi açık pembedir (Anonim, 2002). Peksüslü ve ark. (2014), UPOV test rehberi kullanarak Karadeniz bölgesi tütünlerine yönelik yaptıkları katalog çalışmasında, tescilli çeşitlerin yanı sıra köy popülasyonlarına da yer vermiş ve bu doğrultuda Gümüşhacıköy, Erbaa, Niksar ve Tokat Merkeze ait tütünlerin bazı özelliklerini tespit etmişlerdir. $\mathrm{Bu}$ kapsamda tüm popülasyonlarda yaprak tipi yapışık ve aya şekli geniş eliptik iken yaşmak eni orta-geniş, yaprak ucu orta sivri-sivri, aya kabarcıklığı zayıf-çok zayıf, yaprakta ondülelik çok zayıf-zayıf-orta olarak belirlenmiştir. Bu popülasyonların taç yaprak rengi açık pembe, çiçek kümesi yassı küresel-küresel ve çiçeklenme zamanına göre orta veya geçci karakterdedir. Korubin-Aleksoska ve ark. (2014), ebeveyn olarak kullandıkları Xanthi Djebel XDj-1 tütün çeşidinin bitki boyunun $65 \mathrm{~cm}$, yapraklarının yaşmaklı ve sayısının 17 adet/bitki, yaprak boyunun $17 \mathrm{~cm}$ ve yaprak eninin $8.4 \mathrm{~cm}$ olduğunu tespit etmişlerdir. Aynı araştırmacılar bu basma çeşidinin 43. günde çiçeklenmeye başladığını, 47. günde $\% 50$ çiçeklenmeye ulaştığını ve 70 . günde çiçeklenmenin tamamlandığını aktarmışlardır.

Renk, yaprak boyutları ve içim özellikleri gibi çevresel koşullara bağlı olarak değişebilmektedir. Dış faktörlere bağlı olarak değişmeyen yaprak formu, çiçek rengi ve sümbüle durumu vb ise genetik özellikler olup, özellikle yaprak formu teşhiste kullanılmaktadır (Peksüslü, 1998). Marmara (Dölek, 1984) ve Karadeniz (Karpat, 1989) bölgesi tütünlerinde çalışan araştırmacılar, bitki şekli ve boyu ile yaprak sayısı ve boyutlarının yıl ve çevreden etkilenirken, yaprak formunun değişmediğini bildirmiştir.

Şenbayram ve ark. (2006), oryantal tütünlerde kalite kriterleri açısından önem arz eden doğal stresörleri, yüksek sıcaklık, su azlı̆̆ 1 ve mineral besin elementleri noksanlığ 1 olarak belirtmektedir. Lambers ve ark. (2000), ağır metallerin varlığı, aşırı tuzluluk, eksik yağģs ve azotun önemli stres faktörleri olduğunu, bitkilerin stres kaynaklı olumsuz etkilerden kurtulmak için savunma oluştururken verim kayıpları yaşadıklarını aktarmaktadır. Bu stresörlere karşı bitkiler, fotosentezi ve yaprak alanını azaltma, yaprağı kalınlaştırma, yaprak sayısını artırarak alt yaprakları gölgeleme, yaprak açısını daraltarak güneşten kaçma gibi mekanizmalar geliştirmektedir (Smith ve ark., 2004).

Bruck ve ark. (2008), yaprakta şeker ve özellikle nişasta miktarındaki artışın yaprak kalınlığını da artırdığını bildirmektedir. Oryantal tütünde zamanla uç yaprak sayısının artmasını da bitkinin alt yaprakları koruma amaciyla uyum mekanizması ile oluşturduğu ifade edilmektedir. Yani oryantal tütünlerin anılan yaprak boyutu, rengi, uç açısı, higroskopisitesi, kalınlığı gibi kalite kriterleri aslında onun stresörlere karşı uyum sürecinde ortaya çıkardığı özelliklerdir (Şenbayram ve ark., 2006). 
Yeni harmanlar geliştirmek veya mevcut harmanı sürdürebilmek için tütünlerin fiziksel ve kimyasal özelliklerinin bilinmesi gerekmektedir. Harmanlar; soslar, nemlendiriciler, koku ve lezzet vericiler ile kaplanmasına rağmen içiciler tarafından algılanan öncül kaynak tütündür (Wu ve ark., 1992). Günümüzde tütünler, kimyasal içerikleri (özellikle nikotin ve şeker), sübjektif değerlendirmeler ve içim özelliklerine göre satın alınmakta ve harmanlarda kullanılmaktadır. $\mathrm{Bu}$ nedenle yeni tütün hatlarının islahında bu durumların göz önünde tutulması ve uyum sağladığı belli ekolojiler de yetiştiriciliğinin yapılması gerekmektedir. İstenilen özelliklerde üretim yapılabilmesi, yetiştirilen hat/çeşidin özelliklerinin tam olarak bilinmesi ve uygun üretim koşullarının oluşturulabilmesi ile mümkündür. $\mathrm{Bu}$ çalışma ile materyallerin fenolojik ve morfolojik olarak tanımlanması, tütün 1slahı konusunda yapılacak çalışmalara materyal hakkında bilgi verilmesi ve yöntemin ele alınış biçimi bakımından rehber oluşturulması hedeflenmiştir.

\section{Materyal ve Yöntem}

\subsection{Materyal}

Türkiye Basma tipi tütün yetiştiriciliğinin yapıldığ tüm alanlar 2015 yılında taranarak morfolojik olarak farklı olan bitkiler kendilenerek tohumları toplanmıs, yapılan DNA parmakizi analizi sonucunda 27 hattın farklı olduğu belirlenmiştir (Şekil 1). Bu 27 hattan öne çıkan 21 Basma tütün hattı ile dört standart tütün çeşit/hattı (Xanthi 2A, Nail, Canik 190-5, Xanthi 81) olmak üzere 25 genotip çalışmanın materyalini oluşturmuştur.

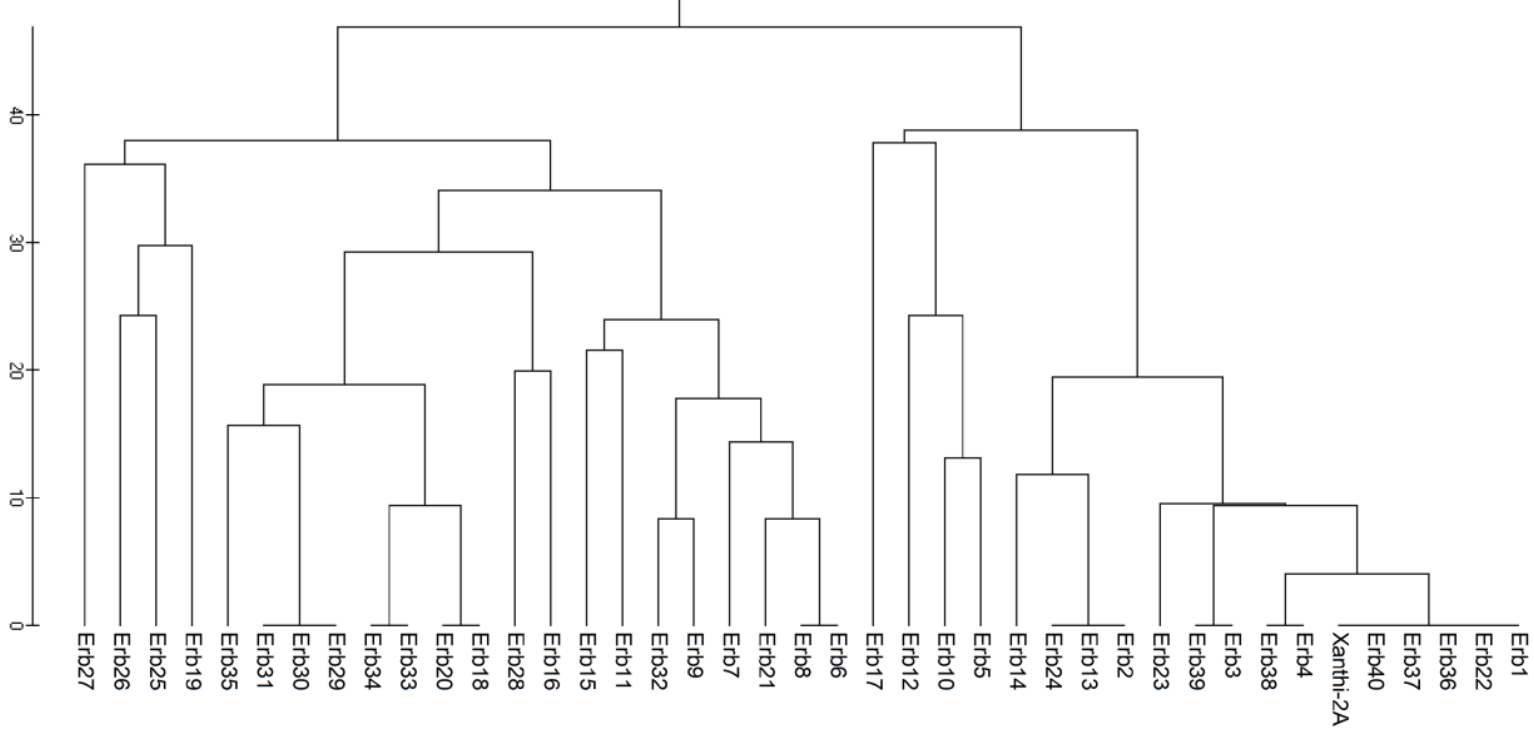

Şekil 1. Tütün genotiplerinin genetik yakınlıklarını gösteren dendrogram

Figure 1. Dendrogram showing the genetic affinity of tobacco genotypes

\subsection{Yöntem}

Araştırma, 2017 yılında Orta Karadeniz Bölgesinin en yoğun tütün üretimi yapılan Gümüşhacıköy ve Bafra ilçeleri ile Erbaa'nın Evciler ve Karayaka köyleri olmak üzere 4 lokasyonda yürütülmüsstür. Çalışma için ihtiyaç duyulan fideler float (su kültürü) sisteminde, torf ortamında, köpük viyollerde yetiştirilmiştir. Tarla denemeleri tesadüf blokları deneme deseninde üç tekrarlamalı olarak yürütülmüştür. Araştırmada kullanılan hat/çeşitlerin bazı morfolojik ve fenolojik özelliklerine ait gözlemler alınmıştır. Bu özellikler belirlenirken "Yeni Bitki Çeşitlerinin Korunması İçin Uluslararası Birlik (UPOV)" tarafindan bütün Nicotiana tabacum L. varyetelerinde kullanıma sunulan test rehberi dikkate alınmıştır (Anonim, 2002). Bu rehberde 35 parametre yer almaktadır. Araştırma kapsamında bu kriterlerden seçilen 10 parametre incelenmiştir.
Parametreler belirlenirken Tohumluk Tescil ve Sertifikasyon Merkez Müdürlüğü'nün Tütün tescil işlemleri için oluşturduğu Teknik Soru Anketi de dikkate alınmıștır (Anonim, 2018). Morfolojik özellikler kapsamında; ${ }^{1}$ yaprak tipi, ${ }^{2}$ yaprağın sapla birleștiği kısmın genişliği (yaşmak eni), ${ }^{3}$ aya şekli, ${ }^{4}$ yaprak ucunun şekli, 5 aya kabarcıklığı, 6 yaprak kenarında ondülelik (kıvrım) ve ${ }^{7}$ alt yüzey orta damar rengi incelenmiştir. Fenolojik özellikler kapsamında; ${ }^{1}$ çiçeklenme zamanı, ${ }^{2}$ taç yaprak rengi, ${ }^{3}$ çiçek kümesi şekli incelenmiştir. Morfolojik özellikler için gözlemler her parselde 10 bitkide, çiçeklenme başında ikinci ana ellerde, fenolojik özelliklerden çiçeklenme zamanı için $\% 50$ çiçeklenme ve diğer çiçek özellikleri için ise her parselde tamamen çiçek açmış 10 bitkide Çizelge 1'de yer alan skalalara göre yapılmış ve Gencer (2002)'e göre frekansları hesaplanmıştır. 
Çizelge 1. Morfolojik ve fenolojik özelliklerin gözlemlerinde kullanılan skalalar

Table 1. Scales used in observing morphological and phenological features

Morfolojik Özellikler

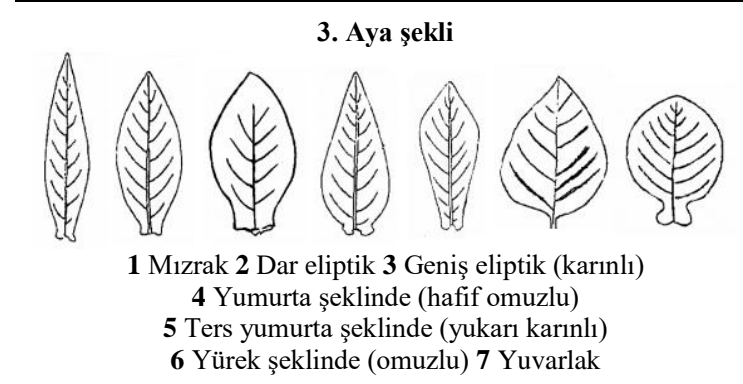

6. Yaprak kenarında ondülelik (kıvrım) 1 Yok veya çok zayıf 3 Zayıf 5 Orta 7 Kuvvetli

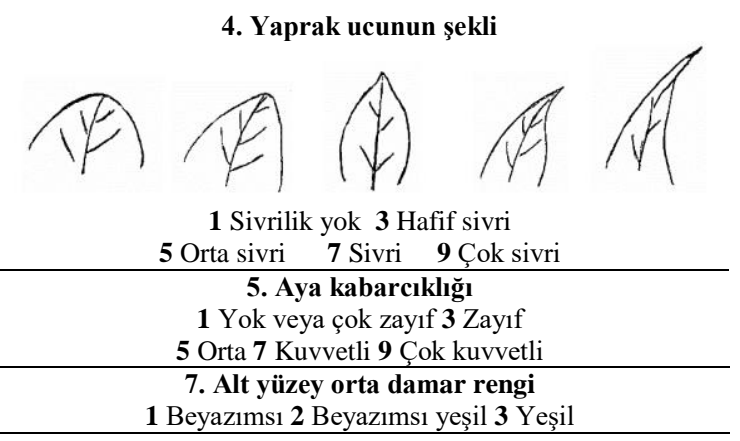

1 Beyazımsı 2 Beyazımsı yeşil 3 Yeşil

\begin{tabular}{|c|c|}
\hline \multicolumn{2}{|c|}{ Fenolojik Özellikler } \\
\hline 1. Ciçeklenme Zamanı & 3. Ciçek Kümesi Sekli \\
\hline (bitkilerin en az \%50'si çiçek açtığında) & 1 Küresel 2 Yassı küresel 3 Ters konik 4 Cift konik \\
\hline 1 Çok erken ( $<25$ gün) 3 Erken (26-50 gün) & \\
\hline 5 Orta (51-60 gün) $\quad 7 \mathrm{Geç}$ (61-70 gün) & \\
\hline 9 Çok geç (>71 gün) & \\
\hline 2. Taç Yaprak Rengi & \\
\hline $\begin{array}{l}1 \text { Beyaz } 2 \text { Açık pembe } \mathbf{3} \text { Pembe } \\
\mathbf{4} \text { Koyu pembe } 5 \text { Kırmızı }\end{array}$ & \\
\hline
\end{tabular}

\section{Bulgular ve Tartışma}

\subsection{Morfolojik özellikler}

Türkiye'de, Basma tütün tipinin yaygın olduğu sahalardan toplanarak seçilen 21 hat ile 4 standarttan oluşan çalışma setinin, incelenen bazı morfolojik karakterlerine ait gözlem sonuçları ve frekansları Çizelge 2 ve 3 ile Şekil 2'de verilmektedir.

Yaprak tipi açısından tamamı yapışık (yaşmaklı/sapsız/zenepsiz) karakter taşıyan hatların $\% 56$ 's1 orta ve \%28'i geniş yaşmak enine sahip olup, ERB-30 ile Canik 190-5'in yaşmak eni dardır. En dar yaşmak eni ERB-11 ve ERB-25 hatlarında tespit edilmiştir. $\mathrm{Bu}$ hatlar aya şekli ile de diğer örneklerden ayrılmakta ve yürek şeklinde (omuzlu) aya şekli göstermektedir. Örneklerin kalan kısmında ise dar $(\% 40)$ veya geniş (\%52) eliptik form hâkimdir (Çizelge 2, 3; Şekil 2). Zenepli (yaşmaksız, saplı) olan tütün tipleri ile karşılaştırıldıklarında, yaşmaklı tipler üretim sürecinde el ile kırım ve dizim işlemlerinde kolaylık sağlamakta, makineli dizime imkân vermekte, yaprak alanında artış ile verime katkı sağlamaktadır. Aynı zamanda yaşmaklı yaprakların yaprak ayası oranının zeneplilere göre daha yüksek olması, tütün harmancılığı açısından da olumlu bir kalite faktörü olarak kabul edilmektedir (Şuben, 1989).Yaprak ucu şekli (yaprak uç açısı) bakımından genotiplerin $\% 48$ 'i orta sivri ve \%44'ü sivri uç açısına sahiptir. ERB-18 ve ERB-35 hatlarında ise yaprak ucu hafif sivri özellik göstermiştir.

Örneklerin yarısından fazlası yok/çok zayıf $(\% 40)$ veya zayıf (\%20) aya kabarcıklığı göstermektedir. $\% 24$ 'ü orta düzeyde aya kabarcıklığına sahip olan genotipler içinde ERB-27 ile ERB-30 kuvvetli ve ERB17 ile ERB-25 çok kuvvetli aya kabarcıklığı ile öne çıkmaktadır (Çizelge 2, 3; Şekil 2). Tütün tiplerinin morfolojik tanımlarında kullanılan yaprak uç açısında, yaprak ayası miktarının daha fazla olması nedeniyle az sivri/küt yani büyük dereceli uç açıları, olumlu kalite faktörü olarak tanımlanmaktadır (Otan ve Apti, 1989).

Aya kabarcıklığı gibi tip özelliğinin belirgin şekilde görülmesine imkan veren yaprakta ondülelik (yaprak kenarlarında kıvrımlılık), örnek grubunda en belirgin olarak orta $(\% 20)$ düzeyde tespit edilmiş, \%80'inde yok/çok zayıf veya zayıf özellik göstermiştir. ERB-12, ERB-19, ERB-27 ve ERB-38 hatlarının diğerlerine göre daha yüksek düzeyde ondülelik özelliğine sahip olduğu görülmüştür. Alt yüzey orta damar rengi açısından beyazımsı özellik gösteren ERB-11 ve Xanthi 81 dışında kalan tüm genotiplerde bu karakter beyazımsı yeşil olarak gözlemlenmiş̧ir (Çizelge 2, 3; Şekil 2).

Basma tütünlerini konu alan çalışmalarda bu tip tütünler, yaşmaklı, eliptik, az sivri-sivri uç açısına sahip olup yaprak yüzeyi orta kabarcıklıdır (Peksüslü, 1998; 
Çamaş ve ark., 2009b, 2011; Yılmaz ve Kınay, 2011). Peksüslü ve ark. (2014)'da basma tütünlerinin yapışı yaprak tipine, geniş eliptik orta-geniş yaşmak enine, orta sivri-sivri uç açısına, çok zayıf/zayıf kabarcıklığa ve çok zayıftan ortaya değişen ondüleliğe sahip olduğunu bildirmişlerdir.

Çalışma sonuçlarımızda örneklerin tamamının yaşmaklı (yapışık) olması， \%84'ünün orta-geniş yaşmağa sahip olması, \%92'sinin eliptik özellik göstermesi, \%92'sinin orta sivri-sivri uç açısına sahip olması, \%84'ünün çok zayıftan ortaya değişen kabarcıklık ve \%80'nin çok zayıf/zayıf ondülelik göstermesi önceki çalışma sonuçları ile örtüşmektedir (Çizelge 2, 3; Şekil 2).

Çalışmada kullanılan standartlar incelendiğinde, Çamaş (1998) Nail popülasyonunun yaşmaklı (yapışık) ve sivri uç açısına sahip olduğunu bildirmiş ve araştırma sonuçlarımızla örtüş̧üğü tespit edilmiştir. Peksüslü ve ark. (2012)'na göre Canik 190-5 çeşidi yaşmakl1, eliptik ve orta sivri uç açısına sahiptir. Çizelge 2

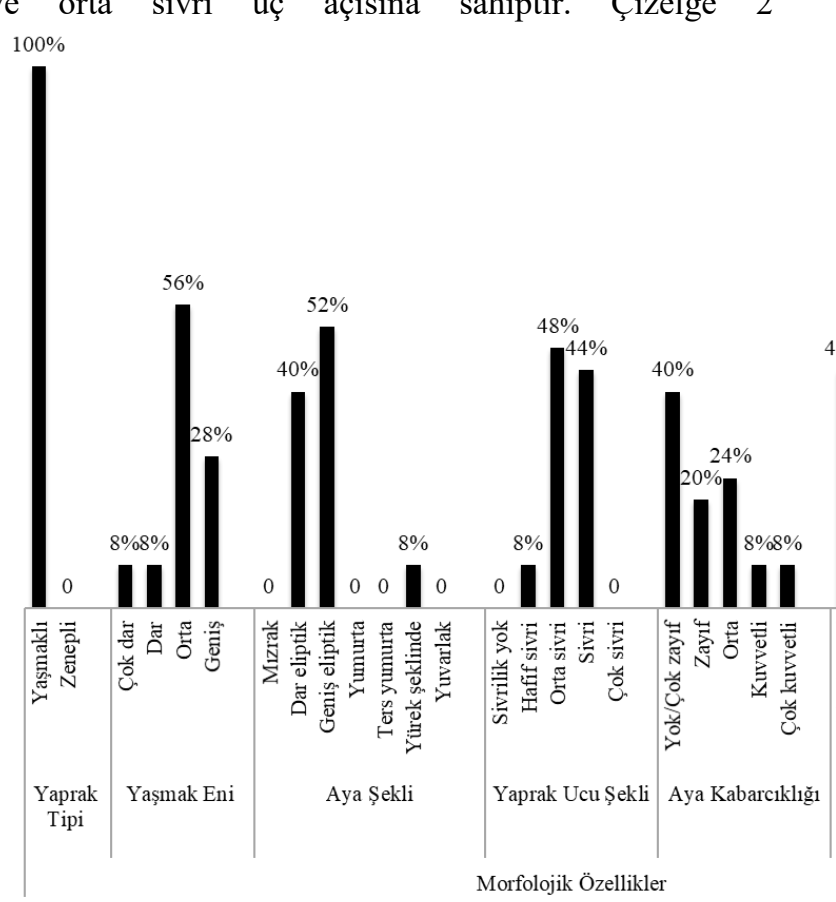

incelendiğinde Canik 190-5 çeşidinin yaşmaklı, eliptik (dar) ve orta sivri uç açısına sahip olduğu görülmektedir.

UPOV test rehberinde Xanthi $2 \mathrm{~A}$ ve Xanthi 81 çeşitleri orta yaşmaklı, geniş eliptik, orta-sivri uç açılı, orta kabarcıklı, ondüleliği orta ve beyazımsı yeşil damarlı olarak ifade edilmektedir (Anonim, 2002). Ülkemizde yapılmış bir başka çalışmada (Anonim, 2012) Xanthi 2A ve Xanthi 81 çeşitleri yaşmaklı, eliptik, az sivri-sivri uç açılı, kabarcıklı olarak tanımlanmıştır. Çalışmamızda Xanthi 2A çeşidi orta yaşmaklı, geniş eliptik, orta sivri uç açıll, orta kabarcık ve zayıf ondülelik gösteren, beyazımsı yeşil alt damar rengine sahip olduğu gözlenmiştir. Xanthi 81 çeşidi ise; orta yaşmaklı, dar eliptik, orta sivri uç açılı, zayıf kabarcık ve ondülelik gösteren, beyazımsı alt yüzey damar rengine sahip bir çeşit olarak tespit edilmiştir (Çizelge 2, 3; Şekil 2).

Şekil 2. Tütün genotiplerinin morfolojik ve fenolojik özelliklerine ait frekansları gösterir grafik

Figure 2. Graph showing the morphological and phenological characteristics of tobacco genotypes

\subsection{Fenolojik özellikler}

Farklı tütün hat ve çeşitlerinde gözlenen bazı fenolojik karakterler ve bu karakterlerin frekansları Çizelge 2 ve 3 ile Şekil 2'de verilmektedir. Bu kapsamda incelenen ilk karakter olarak erkencilik veya geçcilik bilgisini veren, popülasyonda $\% 50$ çiçeklenme tarihleri tespit edilmiş ve genotiplerin \%68'inin 51-60 günde çiçeğe geçtiği anlaşılmıştır. ERB-6, ERB-7, ERB-9, ERB-16, ERB-19, ERB-21, ERB-25 ve ERB35 'in $61-70$ günde $\% 50$ çiçeklenmeyle geçci özellik gösterdiği gözlenmiştir.
Peksüslü (1998) ve Çamaş ve ark. (2011) basma tütün tiplerinin orta erkenci özellik gösterdiğini, Korubin-Aleksoska ve ark. (2014) Xanthi Djebel XDj-1 çeşidinin 47. günde $\% 50$ çiçeklenmeye ulaştığını Peksüslü ve ark. (2014) da ülkemizde yetiştirilen basma tipi tütünlerin orta ve geçci olduğunu bildirmişlerdir. Ek olarak çalışmamızda, Xanthi $2 \mathrm{~A}$ ve Xanthi 81 çeşitlerinin 51-60. günde $\% 50$ çiçeklenmeye ulaşmasından hareketle belirlenen orta erkenci özelliği de Anonim (2002, 2012) ile örtüşmektedir (Çizelge 2, 3; Şekil 2). Daha önceki çalışmalarda basma tip tütünlerde taç yaprak rengi pembe (Peksüslü, 1998; Çamaş ve ark., 
2011) ve açık pembe (Peksüslü ve ark., 2014) olarak tespit edilmiş, çiçek kümesi şeklinin ise küresel (Anonim, 2002; Peksüslü ve ark., 2014) olduğu aktarılmıştır.

Taç yaprak rengi bakımından örnek grubunun $\% 72$ 'si açık pembe ve \%24'ü pembedir. ERB-12 koyu pembe taç yaprak rengi ile araştırma setinin tümünden farklı bir özellik göstermiş̧ir. Araştırma setinin tamamında çiçek kümesi şekli küresel olarak gözlenmiş, sonuçların önceki çalışmalar ile uyum içinde olduğu tespit edilmiştir (Çizelge 2, 3; Şekil 2).

Çizelge 2. Tütün genotiplerinde gözlenen morfolojik ve fenolojik karakterler

Table 2. Morphological and phenological characteristics observed in tobacco genotypes

\begin{tabular}{|c|c|c|c|c|c|c|c|c|c|c|c|}
\hline No & Genotip & $\begin{array}{c}\text { Yaprak } \\
\text { Tipi }\end{array}$ & $\begin{array}{c}\text { Yaşmak } \\
\text { Eni }\end{array}$ & $\begin{array}{l}\text { Aya } \\
\text { Şekli }\end{array}$ & $\begin{array}{c}\text { Yaprak } \\
\text { Ucu Şekli }\end{array}$ & $\begin{array}{c}\text { Aya } \\
\text { Kabarcık }\end{array}$ & $\begin{array}{l}\text { Yaprakta } \\
\text { Ondülelik }\end{array}$ & $\begin{array}{c}\text { Alt Yüzey } \\
\text { Damar Rengi }\end{array}$ & $\begin{array}{c}\text { Çiçeklenme } \\
\text { Zamanı }\end{array}$ & $\begin{array}{c}\text { Taç } \\
\text { Yaprak } \\
\text { Rengi }\end{array}$ & $\begin{array}{c}\text { Çiçek } \\
\text { Kümesi } \\
\text { Şekli }\end{array}$ \\
\hline 1 & ERB-5 & Yaşmaklı & Orta & $\begin{array}{c}\text { Dar } \\
\text { eliptik }\end{array}$ & Sivri & $\begin{array}{c}\text { Yok/çok } \\
\text { zayıf }\end{array}$ & $\begin{array}{c}\text { Yok/çok } \\
\text { zayif }\end{array}$ & $\begin{array}{c}\text { Beyazımsı } \\
\text { yesil }\end{array}$ & $\begin{array}{c}\text { Orta } \\
\text { (51-60 gün) }\end{array}$ & $\begin{array}{c}\text { Açık } \\
\text { pembe }\end{array}$ & Küresel \\
\hline 2 & ERB-6 & Yaşmaklı & Orta & $\begin{array}{l}\text { Geniş } \\
\text { eliptik }\end{array}$ & Orta sivri & $\begin{array}{l}\text { Yok/çok } \\
\text { zayıf }\end{array}$ & $\begin{array}{c}\text { Yok/çok } \\
\text { zayif }\end{array}$ & $\begin{array}{l}\text { Beyazımsı } \\
\text { yeșil }\end{array}$ & $\begin{array}{c}\text { Geç } \\
\text { (61-70 gün) }\end{array}$ & $\begin{array}{l}\text { Açık } \\
\text { pembe }\end{array}$ & Küresel \\
\hline 3 & ERB-7 & Yaşmaklı & Orta & $\begin{array}{l}\text { Dar } \\
\text { eliptik }\end{array}$ & Sivri & $\begin{array}{l}\text { Yok/çok } \\
\text { zayıf }\end{array}$ & $\begin{array}{c}\text { Yok/çok } \\
\text { zayif }\end{array}$ & $\begin{array}{l}\text { Beyazımsı } \\
\text { yeşil }\end{array}$ & $\begin{array}{c}\text { Geç } \\
\text { (61-70 gün) }\end{array}$ & $\begin{array}{l}\text { Açık } \\
\text { pembe }\end{array}$ & Küresel \\
\hline 4 & ERB-9 & Yaşmaklı & Orta & $\begin{array}{l}\text { Dar } \\
\text { eliptik }\end{array}$ & Sivri & $\begin{array}{c}\text { Yok/çok } \\
\text { zaylf }\end{array}$ & $\begin{array}{c}\text { Yok/çok } \\
\text { zayif }\end{array}$ & $\begin{array}{l}\text { Beyazımsı } \\
\text { yeşil }\end{array}$ & $\begin{array}{c}\text { Geç } \\
\text { (61-70 gün) }\end{array}$ & Pembe & Küresel \\
\hline 5 & ERB-11 & Yaşmaklı & Çok dar & $\begin{array}{l}\text { Yürek } \\
\text { şekli }\end{array}$ & Orta sivri & $\begin{array}{c}\text { Yok/çok } \\
\text { zayıf }\end{array}$ & $\begin{array}{c}\text { Yok/çok } \\
\text { zayıf }\end{array}$ & Beyazımsı & $\begin{array}{c}\text { Orta } \\
\text { (51-60 gün) }\end{array}$ & $\begin{array}{c}\text { Açık } \\
\text { pembe }\end{array}$ & Küresel \\
\hline 6 & ERB-12 & Yaşmaklı & Geniş & $\begin{array}{l}\text { Dar } \\
\text { eliptik }\end{array}$ & Sivri & $\begin{array}{l}\text { Yok/çok } \\
\text { zayıf }\end{array}$ & Orta & $\begin{array}{l}\text { Beyazımsı } \\
\text { yeşil }\end{array}$ & $\begin{array}{c}\text { Orta } \\
\text { (51-60 gün) }\end{array}$ & $\begin{array}{l}\text { Koyu } \\
\text { pembe }\end{array}$ & Küresel \\
\hline 7 & ERB-13 & Yaşmaklı & Orta & $\begin{array}{l}\text { Dar } \\
\text { eliptik }\end{array}$ & Orta sivri & Zayıf & Zayıf & $\begin{array}{l}\text { Beyazımsı } \\
\text { yeşil }\end{array}$ & $\begin{array}{c}\text { Orta } \\
\text { (51-60 gün) }\end{array}$ & Pembe & Küresel \\
\hline 8 & ERB-14 & Yaşmaklı & Orta & $\begin{array}{l}\text { Dar } \\
\text { eliptik }\end{array}$ & Orta sivri & $\begin{array}{c}\text { Yok/çok } \\
\text { zayıf }\end{array}$ & Zayıf & $\begin{array}{l}\text { Beyazımsı } \\
\text { yeşil }\end{array}$ & $\begin{array}{c}\text { Orta } \\
\text { (51-60 gün) }\end{array}$ & $\begin{array}{l}\text { Açık } \\
\text { pembe }\end{array}$ & Küresel \\
\hline 9 & ERB-15 & Yaşmaklı & Orta & $\begin{array}{l}\text { Geniş } \\
\text { eliptik }\end{array}$ & Orta sivri & $\begin{array}{c}\text { Yok/çok } \\
\text { zayıf }\end{array}$ & $\begin{array}{c}\text { Yok/çok } \\
\text { zayif }\end{array}$ & $\begin{array}{l}\text { Beyazımsı } \\
\text { yeșil }\end{array}$ & $\begin{array}{l}\text { Orta } \\
\text { (51-60 gün) }\end{array}$ & Pembe & Küresel \\
\hline 10 & ERB-16 & Yaşmaklı & Orta & $\begin{array}{l}\text { Geniş } \\
\text { eliptik }\end{array}$ & Sivri & Zayıf & $\begin{array}{c}\text { Yok/çok } \\
\text { zayif }\end{array}$ & $\begin{array}{l}\text { Beyazıms } \\
\text { yeşil }\end{array}$ & $\begin{array}{c}\text { Geç } \\
\text { (61-70 gün) }\end{array}$ & $\begin{array}{c}\text { Açık } \\
\text { pembe }\end{array}$ & Küresel \\
\hline 11 & ERB-17 & Yaşmaklı & Geniş & $\begin{array}{l}\text { Geniş } \\
\text { eliptik }\end{array}$ & Sivri & $\begin{array}{c}\text { Çok } \\
\text { kuvvetli }\end{array}$ & $\begin{array}{c}\text { Yok/çok } \\
\text { zayıf }\end{array}$ & $\begin{array}{l}\text { Beyazımsı } \\
\text { yeşil }\end{array}$ & $\begin{array}{c}\text { Orta } \\
\text { (51-60 gün) }\end{array}$ & Pembe & Küresel \\
\hline 12 & ERB-18 & Yaşmaklı & Orta & $\begin{array}{l}\text { Geniş } \\
\text { eliptik }\end{array}$ & Hafif sivri & $\begin{array}{l}\text { Yok/çok } \\
\text { zayıf }\end{array}$ & Zayıf & $\begin{array}{l}\text { Beyazımsı } \\
\text { yeşil }\end{array}$ & $\begin{array}{c}\text { Orta } \\
\text { (51-60 gün) }\end{array}$ & $\begin{array}{l}\text { Açık } \\
\text { pembe }\end{array}$ & Küresel \\
\hline 13 & ERB-19 & Yaşmaklı & Geniş & $\begin{array}{l}\text { Geniş } \\
\text { eliptik }\end{array}$ & Orta sivri & Orta & Orta & $\begin{array}{l}\text { Beyazımsı } \\
\text { yeşil }\end{array}$ & $\begin{array}{c}\text { Geç } \\
\text { (61-70 gün) }\end{array}$ & $\begin{array}{c}\text { Açık } \\
\text { pembe }\end{array}$ & Küresel \\
\hline 14 & ERB-21 & Yaşmaklı & Geniş & $\begin{array}{l}\text { Geniş } \\
\text { eliptik }\end{array}$ & Sivri & Zayıf & Zayıf & $\begin{array}{l}\text { Beyazımsi } \\
\text { yeşil }\end{array}$ & $\begin{array}{c}\text { Geç } \\
\text { (61-70 gün) }\end{array}$ & $\begin{array}{l}\text { Açık } \\
\text { pembe }\end{array}$ & Küresel \\
\hline 15 & ERB-23 & Yaşmaklı & Orta & $\begin{array}{l}\text { Dar } \\
\text { eliptik }\end{array}$ & Sivri & Orta & Orta & $\begin{array}{l}\text { Beyazımsı } \\
\text { yeșil }\end{array}$ & $\begin{array}{c}\text { Orta } \\
\text { (51-60 gün) }\end{array}$ & $\begin{array}{l}\text { Açık } \\
\text { pembe }\end{array}$ & Küresel \\
\hline 16 & ERB-25 & Yaşmaklı & Çok dar & $\begin{array}{l}\text { Yürek } \\
\text { şekli }\end{array}$ & Sivri & $\begin{array}{c}\text { Çok } \\
\text { kuvvetli }\end{array}$ & $\begin{array}{c}\text { Yok/çok } \\
\text { zayıf }\end{array}$ & $\begin{array}{l}\text { Beyazıms } \\
\text { yeşil }\end{array}$ & $\begin{array}{c}\text { Geç } \\
\text { (61-70 gün) }\end{array}$ & $\begin{array}{l}\text { Açık } \\
\text { pembe }\end{array}$ & Küresel \\
\hline 17 & ERB-26 & Yaşmaklı & Geniş & $\begin{array}{l}\text { Geniş } \\
\text { eliptik }\end{array}$ & Orta sivri & Zayıf & Zayıf & $\begin{array}{l}\text { Beyazımsi } \\
\text { yeşil }\end{array}$ & $\begin{array}{c}\text { Orta } \\
\text { (51-60 gün) }\end{array}$ & $\begin{array}{l}\text { Açık } \\
\text { pembe }\end{array}$ & Küresel \\
\hline 18 & ERB-27 & Yaşmaklı & Geniş & $\begin{array}{l}\text { Geniş } \\
\text { eliptik }\end{array}$ & Sivri & Kuvvetli & Orta & $\begin{array}{l}\text { Beyazımsı } \\
\text { yeşil }\end{array}$ & $\begin{array}{c}\text { Orta } \\
\text { (51-60 gün) }\end{array}$ & $\begin{array}{l}\text { Açık } \\
\text { pembe }\end{array}$ & Küresel \\
\hline 19 & ERB-30 & Yaşmaklı & Dar & $\begin{array}{l}\text { Geniş } \\
\text { eliptik }\end{array}$ & Orta sivri & Kuvvetli & Zayıf & $\begin{array}{l}\text { Beyazımsı } \\
\text { yeşil }\end{array}$ & $\begin{array}{c}\text { Orta } \\
\text { (51-60 gün) }\end{array}$ & $\begin{array}{c}\text { Açık } \\
\text { pembe }\end{array}$ & Küresel \\
\hline 20 & ERB-35 & Yaşmaklı & Orta & $\begin{array}{l}\text { Geniş } \\
\text { eliptik }\end{array}$ & Hafif sivri & Orta & Zayıf & $\begin{array}{l}\text { Beyazımsı } \\
\text { yeşil }\end{array}$ & $\begin{array}{c}\text { Geç } \\
\text { (61-70 gün) }\end{array}$ & $\begin{array}{l}\text { Açık } \\
\text { pembe }\end{array}$ & Küresel \\
\hline 21 & ERB-38 & Yaşmaklı & Geniş & $\begin{array}{l}\text { Geniş } \\
\text { eliptik }\end{array}$ & Orta sivri & Orta & Orta & $\begin{array}{l}\text { Beyazımsı } \\
\text { yeșil }\end{array}$ & $\begin{array}{c}\text { Orta } \\
\text { (51-60 gün) }\end{array}$ & Pembe & Küresel \\
\hline 22 & Xanthi 2A & Yaşmaklı & Orta & $\begin{array}{l}\text { Geniş } \\
\text { eliptik }\end{array}$ & Orta sivri & Orta & Zayıf & $\begin{array}{l}\text { Beyazımsı } \\
\text { yeşil }\end{array}$ & $\begin{array}{c}\text { Orta } \\
\text { (51-60 gün) }\end{array}$ & $\begin{array}{l}\text { Açık } \\
\text { pembe }\end{array}$ & Küresel \\
\hline 23 & Nail & Yaşmaklı & Orta & $\begin{array}{l}\text { Dar } \\
\text { eliptik }\end{array}$ & Sivri & Orta & $\begin{array}{c}\text { Yok/çok } \\
\text { zayıf }\end{array}$ & $\begin{array}{l}\text { Beyazımsı } \\
\text { yeşil }\end{array}$ & $\begin{array}{c}\text { Orta } \\
\text { (51-60 gün) }\end{array}$ & Pembe & Küresel \\
\hline 24 & Canik 190-5 & Yaşmaklı & Dar & $\begin{array}{l}\text { Dar } \\
\text { eliptik }\end{array}$ & Orta sivri & $\begin{array}{c}\text { Yok/çok } \\
\text { zayıf }\end{array}$ & $\begin{array}{c}\text { Yok/çok } \\
\text { zayıf }\end{array}$ & $\begin{array}{l}\text { Beyazımsı } \\
\text { yeşil }\end{array}$ & $\begin{array}{c}\text { Orta } \\
\text { (51-60 gün) }\end{array}$ & $\begin{array}{c}\text { Açık } \\
\text { pembe }\end{array}$ & Küresel \\
\hline 25 & Xanthi 81 & Yaşmaklı & Orta & $\begin{array}{l}\text { Dar } \\
\text { eliptik }\end{array}$ & Orta sivri & Zayıf & Zayıf & Beyazımsı & $\begin{array}{c}\text { Orta } \\
\text { (51-60 gün) }\end{array}$ & $\begin{array}{l}\text { Açık } \\
\text { pembe }\end{array}$ & Küresel \\
\hline
\end{tabular}

Çizelge 3. Tütün genotiplerinde gözlenen karakterlere ait frekans değerleri

Table 3. Frequency values of the characters observed in tobacco genotypes 


\begin{tabular}{ll}
\hline & \multicolumn{1}{c}{ Morfolojik Özellikler } \\
\hline Yaprak Tipi & Yaşmaklı (\%100) \\
Yaşmak Eni & Çok dar (\%8) Dar (\%8) Orta (\%56) Geniş (\%28) \\
Aya Şekli & Dar eliptik (\%40) Geniş eliptik (\%52) Yürek şeklinde (\%8) \\
Yaprak Ucu Şekli & Hafif sivri (\%8) Orta sivri (\%48) Sivri (\%44) \\
Aya Kabarcıklığı & Yok/Çok zayıf (\%40) Zayıf (\%20) Orta (\%24) Kuvvetli (\%8) Çok kuvvetli (\%8) \\
Yaprakta Ondülelik & Yok/Çok zayıf (\%44) Zayıf (\%36) Orta (\%20) \\
Alt Yüzey Orta Damar Rengi & Beyazımsı (\%8) Beyazımsı yeşil (\%92) \\
\hline & \\
\hline Çiçeklenme Zamanı & Orta (\%68) Geç (\%32) \\
Taç Yaprak Rengi & Açılk pembe (\%72) Pembe (\%24) Koyu pembe (\%4) \\
Çiçek Kümesi Şekli & Küresel (\%100) \\
\hline
\end{tabular}

\section{Sonuc}

Elde edilen sonuçlara göre; genotiplerin tamamı yaşmakl1, \%84'ü orta-geniş yaşmak enine sahip, \%92'si dar yada geniş eliptik, \%92'si orta sivri yada sivri yaprak ucuna sahip, aya kabarcıklığ 1 yok/çok zayıf (\%40), zayif (\%20) veya orta (\%24) olan, \%56's1 zayif veya orta ondüleliğe sahip ve alt yüzey orta damar rengi \%92'si beyazımsı yeşildir. Genotiplerin \%32'si geçci olup, taç yaprak rengi \%72'si açık pembe ve tamamı küresel çiçek şekline sahiptir. $\mathrm{Bu}$ çalışma ile materyallerin fenolojik ve morfolojik olarak

\section{Kaynaklar}

Anonim, 2002. International union for the protection of new varieties of plants (UPOV) Guidelines for the Conduct of Tests for Distinctness, Uniformity and Stability, Tobacco (Nicotiana tabacum L.). TG/195/1. http://www.upov.int/ en/publications/tgrom/tg195/tg 195 1.pdf (Erişim tarihi: 27.01.2017).

Anonim, 2012. Basma Tütünü Yetiştirme Tekniği. Ege İhracatçı Birlikleri, Ege Tütün İhracatçıları Birliği Yayınları, İzmir.

Anonim, 2018. Tohumluk Tescil ve Sertifikasyon Merkez Müdürlüğü (TTSM). Tescil başvuru aşaması teknik soru anketleri. Tütün (Nicotiana tabacum L.). http://www.

tarim.gov.tr/BUGEM/TTSM/Sayfalar/Detay.aspx?S ayfaId=44 (Erişim tarihi: 31.10 .2018 ).

Bruck, H., Jureit, C., Hermann, M., Schulz, A., Sattelmacher, B., 2008. Effect of water and nitrogen supply on water use efficiency and carbon isotope discrimination in Edible Canna (Canna edulis KerGawler). Plant Biology, 3(4): 326-334. https://doi.org/10.1055/s-2001-16450. tanımlanması, tütün 1slahı konusunda yapılacak çalışmalara materyal hakkında bilgi verilmesi ve yöntemin ele alınış biçimi bakımından rehber oluşturulması hedeflenmiştir.

\section{Teşekkür}

$\mathrm{Bu}$ çalışma, Tütün ve Alkol Piyasası Düzenleme Kurumu tarafindan "Tokat Yöresi Basma Tipi Tütünlerde Üstün Özelliklere Sahip Hatların Belirlenmesi" projesi kapsamında desteklenmiştir.

Çamaş, N., 1998. Tütün (Nicotiana tabacum L.) melezlerinde bazı kantitatif özelliklerinin kalıtımının line $\mathrm{x}$ tester yöntemi ile analizi. Doktora Tezi. Ondokuz Mayıs Üniversitesi Fen Bilimleri Enstitüsü, Tarla Bitkileri Anabilim Dalı, 96 s, Samsun.

Çamaş, N., Çalışkan, Ö., Odabaş, M.S., Ayan, A.K., 2009a. Organik kökenli gübre dozlarının Esendal tütün çeşidinin verimi ve kalitesi üzerine etkileri. Türkiye VIII. Tarla Bitkileri Kongresi (19-22 Ekim 2009, Hatay) Bildirileri, 251-255.

Çamaş, N., Karaali, H., Çalışkan, Ö., Kurt, D., 2009 b. Basma tütün çeşit ve hatlarının Gümüşhacıköy şartlarında verim ve verim unsurlarının belirlenmesi. Türkiye VIII. Tarla Bitkileri Kongresi, (19-22 Ekim 2009, Hatay) Bildirileri, 247-250.

Çamaş, N., Karaali, H., Kurt, D., Kınay, A., 2011. Orta Karadeniz bölgesi basma tipi tütün yetiştiriciliğinde kalite unsurlarının değerlendirilmesi. Türkiye IX. Tarla Bitkileri Kongresi (12-15 Eylül 2011, Bursa) Bildirileri, 908-913.

Dölek, İ., 1984. Marmara bölgesi Nicotiana tabacum L. safhat çeşitlerinin bazı morfolojik özellikleri. Doktora Tezi. Tekel Enstitüsü Yayınları, Yayın No: 306, İstanbul. 
Gencer, A.S., 2002. Türkiye tütün popülasyonlarında bazı özelliklerin saptanması, I: Marmara ve Karadeniz Bölgeleri. Journal of Aegean Agricultural Research Institute, Anadolu, 12(1): 83-95.

Karpat, H., 1989. Samsun-Bafra tütün çeşitlerinin taksonomik (Nicotiana tabacum L.) özellikleri üzerine araştırmalar. Doktora Tezi. İstanbul Üniversitesi Fen Bilimleri Enstitüsü, Biyoloji Anabilim Dalı, 194 s, İstanbul.

Korubin-Aleksoska, A., Miceska, G., Aleksoski, J., 2014. Plant breeding for creation of late-maturing oriental tobacco genotypes. Тутун/Tobacco, 64 (16): $5-11$.

Lambers, H., Chapin, S.F., Pons, L.P., 2000. Plant physiological ecology. Springer-Verlag, 840 pp, New York.

Otan, H., Apti, R. 1989. Tütün. T.C. T.O.K.İ.B. Ege T.A.E. Yay. No: 83, 89 s, İzmir.

Peksüslü, A., 1998. Bazı Türk tütün çeşitlerinin İzmirBornova koşullarında morfolojik fizyolojik ve biyokimyasal özellikleri. Doktora Tezi. Ege Üniversitesi Fen Bilimleri Enstitüsü, Tarla Bitkileri Anabilim Dalı, 79 s, İzmir.

Peksüslü, A., Y1lmaz, İ., İnal, A., Kartal, H., 2012. Tobacco genotypes of Turkey. Journal of Aegean
Agricultural Research Institute, Anadolu, 22(2): 8290.

Peksüslü, A., Yılmaz, İ., İnal, A., Kartal, H., 2014. Türkiye tütün kaynakları: Karadeniz bölgesi tütünleri. TC Gıda Tarım ve Hayvancılık Bakanlığı Ege Tarımsal Araştırma Enstitüsü Yayın No: 153, İzmir.

Smith, A.M., Zeeman, S.C., Thorneycroft, D., Smith, S.M., 2004. Starch mobilization in leaves. Journal of Experimental Botany, 54(382): 577-583. https://doi.org/10.1093/jxb/erg036.

Şenbayram, M., Ekren, S., Sekin, S., 2006. Ekolojik koşulların ve besin elementlerinin oryantal tütün kalitesi üzerindeki etkileri. Tütün Eksperleri Derneği Bülteni, 75: 13-17.

Şuben, M., 1989. Özel Harmancılık. İstanbul Üniversitesi Yayın No: 3558, İstanbul.

Wu, Z., Weeks, W.W., Long, R.C., 1992. Contribution of neutral volatiles to flavor intensity of tobacco during smoking. J. Agric. Food. Chem., 40: 19171921. https://doi.org/10.1021/jf00022a038.

Yılmaz, G., Kınay, A., 2011. Tütünde (Nicotiana tabacum L.) farklı azot dozlarının verim ve kalite özelliklerine etkileri. IX. Tarla Bitkileri Kongresi (12-15 Eylül 2011, Bursa) Bildirileri Kitabı, 2: 951956. 